\title{
Arsenic retention and transport behavior in the presence of typical anionic and nonionic surfactants
}

\author{
Chuan Liang ${ }^{1, * *}$, Xianliang Wang ${ }^{2,3, * *}$, Xianjia Peng ${ }^{1, *}$ \\ 1. State Key Laboratory of Environmental Aquatic Chemistry, Research Center for Eco-Environmental Sciences, Chinese Academy of Sciences, \\ Beijing 100085, China \\ 2. Institute of Environmental Health and Related Product Safety, Chinese Centre for Disease Control and Prevention, Beijing 100021, China \\ 3. State Key Laboratory of Environmental Criteria and Risk Assessment, Chinese Research Academy of Environmental Sciences, Beijing 100012, China
}

\section{A R T I C L E I N F O}

\section{Article history:}

Received 30 June 2015

Revised 6 December 2015

Accepted 14 December 2015

Available online 7 January 2016

\section{Keywords:}

Surfactants

Arsenic

Retention

Transport

\begin{abstract}
A B S T R A C T
The massive production and wide use of surfactants have resulted in a large amount of surfactant residuals being discharged into the environment, which could have an impact on arsenic behavior. In the present study, the influence of the anionic surfactant sodium dodecyl benzene sulfonate (SDBS) and nonionic surfactant polyethylene glycol octylphenyl ether (Triton X-100) on arsenic behavior was investigated in batch and column tests. The presence of SDBS and Triton X-100 reduced arsenic retention onto ferrihydrite (FH), enhanced arsenic transport through FH coated sand (FH-sand) columns and promoted arsenic release from the FH surface. With coexisting surfactants in solution, the equilibrium adsorbed amount of arsenic on $\mathrm{FH}$ decreased by up to $29.7 \%$ and the adsorption rate decreased by up to $52.3 \%$. Pre-coating with surfactants caused a decrease in the adsorbed amount and adsorption rate of arsenic by up to $15.1 \%$ and $58.3 \%$, respectively. Because of the adsorption attenuation caused by surfactants, breakthrough of $\mathrm{As}(\mathrm{V})$ and $\mathrm{As}(\mathrm{III})$ with SDBS in columns packed with FH-sand was $23.8 \%$ and $14.3 \%$ faster than that in those without SDBS, respectively. In columns packed with SDBS-coated FH-sand, transport of arsenic was enhanced to a greater extent. Breakthrough of $\mathrm{As}(\mathrm{V})$ and $\mathrm{As}(\mathrm{III})$ was $52.4 \%$ and $43.8 \%$ faster and the cumulative retention amount was $44.5 \%$ and $57.3 \%$ less than that in pure FH-sand column systems, respectively. Mobilization of arsenic by surfactants increased with the increase of the initial adsorbed amount of arsenic. The cumulative release amount of $\mathrm{As}(\mathrm{V})$ and $\mathrm{As}(\mathrm{III})$ from the packed column reached $10.8 \%$ and $36.0 \%$, respectively.
\end{abstract}

(C) 2015 The Research Center for Eco-Environmental Sciences, Chinese Academy of Sciences.

Published by Elsevier B.V.

\section{Introduction}

Surfactants are generally a group of chemicals consisting of both polar and nonpolar groups. Due to their solubilization and cleaning properties, surfactants are widely used in household detergents, the textile industry, and in smelting and mining activities. The world production of surfactants has been up to 18.2 million tons annually (Céspedes et al., 2008; Ying, 2006). According to the properties of their polar groups, surfactants are mainly divided into anionic type, cationic type and nonionic type, among which anionic and nonionic surfactants are most widely used. After being used,

\footnotetext{
* Corresponding author. E-mail: xjpeng@rcees.ac.cn (Xianjia Peng).

** These authors contributed equally to this study.
} 
surfactant residuals are discharged into sewage treatment plants or directly to environmental media such as water, soil and sediment. This leads to different levels of surfactants being detected in environmental compartments (Lara-Martín et al., 2006, 2008; Marcomini et al., 2000; Shalaby, 2007; Ying et al., 2002; Ying, 2006). The distribution and behavior of surfactants in the environment have been widely studied to assess the environmental risks. When entering the environment, surfactants tend to be adsorbed onto particles and sediments, thus altering the physicochemical characteristics of particle surfaces and influencing the environmental behavior of other pollutants. It is suggested that surfactants could exert significant effects on the adsorption and release of organic matters and heavy metals (Pan et al., 2009; Song et al., 2008; Tripathi and Brown, 2008; Turner and $\mathrm{Xu}, 2008)$. The mechanisms mainly include adsorption competition, complexation reactions, solubilization and electrostatic repulsion (Clara et al., 2007; de Wolf and Feijtel, 1998; Fu et al., 2007; Kloepper-Sams et al., 1996; Lara-Martin et al., 2008; Shalaby, 2007). Considering the widespread use of surfactants and conspicuous toxicity of arsenic, this study investigated the potential effects of surfactants on the behavior of arsenic in the environment.

Arsenic retention on particles and transport in sediments are two main factors controlling its bioavailability and toxicity. Both processes are to a great extent influenced by coexisting substances such as natural organic matters (NOM) and anions. It has been well documented that such substances may reduce arsenic adsorption and enhance arsenic transport through adsorption competition, complexation reactions, anion exchange and electrostatic repulsion (Barringer et al., 2011; Dias et al., 2009; Garcia-Sanchez et al., 2010; Garcia et al., 2007; Guo et al., 2014; He et al., 2010; Radloff et al., 2007; Reza et al., 2010; Serfes et al., 2003; Zheng et al., 2004). Thus, through such mechanisms, surfactant molecules may potentially influence arsenic adsorption and transport behavior in the environment.

In natural environments, there could be three scenarios in which surfactants influence arsenic adsorption and mobilization (Sharma et al., 2011). The first scenario represents water environments where surfactants coexist with arsenic. There could be adsorption competition, as both substances are likely to be adsorbed by particulate matters. The second scenario indicates that wastewater containing arsenic could be discharged into water and sediments that are coated with surfactants. As known under circumstances such as mining sites and wastewater discharge locations, large amounts of surfactants could be adsorbed onto sediments. The occupation of adsorption sites on particle surfaces by surfactants may result in a reduction of arsenic adsorption. In the third scenario, opposite to the second, arsenic-contaminated sediments may be exposed to surfactants, leading to the mobilization of arsenic.

Based on the situations described above, a typical anionic surfactant, sodium dodecyl benzene sulfonate (SDBS), and nonionic surfactant, polyethylene glycol octylphenyl ether (Triton X-100), were employed to investigate the influence of surfactants on arsenic adsorption and mobilization. Synthetic ferrihydrite $(\mathrm{FH})$ was chosen as a representative model mineral that has great affinity with arsenic in the environment. Specifically, both batch and column experiments were conducted to examine: (1) adsorption of arsenic onto $\mathrm{FH}$ in the presence of surfactants; (2) arsenic transport through FH-coated sand (FH-sand) columns in the presence of surfactants and arsenic transport through columns packed with surfactant-coated FH-sand; and (3) mobilization of adsorbed arsenic from $\mathrm{FH}$ and FH-sand by surfactants.

\section{Materials and methods}

\subsection{Materials}

Chemicals used in the experiments were of analytical grade and used without further purification. Stock solutions of $1000 \mathrm{mg} / \mathrm{L} \mathrm{As}(\mathrm{V})$ and $\mathrm{As}(\mathrm{III})$ were prepared by dissolving $4.160 \mathrm{~g} \mathrm{Na} \mathrm{NAsO}_{4} \cdot 7 \mathrm{H}_{2} \mathrm{O}$ and $1.732 \mathrm{~g} \mathrm{NaAsO}$ into $1.0 \mathrm{~L}$ de-ionized water, respectively. Stock solutions of SDBS and Triton X-100 were both prepared by dissolving 1.000 g surfactant in $1.0 \mathrm{~L}$ de-ionized water. Characteristics of surfactants are shown in Table 1. De-ionized water used for all As(III) experiments was deoxygenated by boiling for $10 \mathrm{~min}$ and cooling down to room temperature before use.

\subsection{Synthesis of FH and FH-sand}

FH used in this study was synthesized according to Schwertmann's method (Sharma et al., 2011). Under continuous stirring, a solution of $1.0 \mathrm{~mol} / \mathrm{L} \mathrm{KOH}$ was added to a $500 \mathrm{~mL}$ solution of $0.2 \mathrm{~mol} / \mathrm{L} \mathrm{Fe}\left(\mathrm{NO}_{3}\right)_{3} \cdot 9 \mathrm{H}_{2} \mathrm{O}$ at a rate of approximately $50 \mathrm{~mL} / \mathrm{min}$, till the $\mathrm{pH}$ of the solution reached 7.5. The mixture was aged for $2 \mathrm{hr}$, then the supernatant was removed and the suspension was washed three times with de-ionized water. Then the suspension was centrifuged at $5000 \mathrm{r} / \mathrm{min}$ for $10 \mathrm{~min}$, and the precipitate was resuspended in $1.0 \mathrm{~L}$ de-ionized water. The FH concentration of the resulting suspension was approximately $10 \mathrm{~g} / \mathrm{L}$. The specific surface area of the freeze-dried FH particles was $81.9 \pm 2.1 \mathrm{~m}^{2} / \mathrm{g}$, measured using the BET- $\mathrm{N}_{2}$ adsorption method. The FH-sand was prepared by mixing $100.0 \mathrm{~g}$ washed quartz sand with an average particle diameter of $2.0 \mathrm{~mm}$ with the $\mathrm{FH}$ suspension and aging for $24 \mathrm{hr}$. The particles were dried at $50.0^{\circ} \mathrm{C}$ for $24 \mathrm{hr}$ and the residual was removed using a 2-mm sieve. The iron content of FH-sand was $120 \mathrm{mg} / \mathrm{kg}$, tested by Inductively Coupled Plasma Mass Spectroscopy (ICP-MS, Agilent 7500a, USA) after extraction with $0.1 \mathrm{~mol} / \mathrm{L} \mathrm{HCl}$.

\subsection{Adsorption isotherm of surfactants on $\mathrm{FH}$}

Experimental details and results regarding the adsorption isotherm of SDBS and Triton X-100 onto FH are given in Appendix A Fig. S1.

\begin{tabular}{llcll}
\multicolumn{4}{l}{ Table 1 - Characteristics of surfactants. } \\
Surfactant & Type & MW (g/mol) & $\begin{array}{l}\text { Molecular } \\
\text { formation }\end{array}$ & $\begin{array}{c}\mathrm{CMC} \\
(\mathrm{mg} / \mathrm{L})\end{array}$ \\
\hline SDBS & Anionic & 348.48 & $\mathrm{C}_{18} \mathrm{H}_{29} \mathrm{SO}_{3} \mathrm{Na}$ & 522 \\
Triton X-100 & Nonionic & 646.86 & $\mathrm{C}_{14} \mathrm{HO}_{22}\left(\mathrm{C}_{2} \mathrm{H}_{4} \mathrm{O}\right)_{10}$ & 150 \\
\hline
\end{tabular}

SDBS: sodium dodecyl benzene sulfonate.

CMC: critical micelle concentration. 


\subsection{Influence of surfactants on arsenic adsorption isotherm onto $\mathrm{FH}$}

The adsorption isotherm of arsenic in the presence of surfactants was investigated. In a batch of $50-\mathrm{mL}$ centrifuge tubes, $40 \mathrm{~mL}$ mixtures containing $0.1 \mathrm{~g} / \mathrm{L} \mathrm{FH}, 0$ or $50 \mathrm{mg} / \mathrm{L}$ surfactant, and different concentrations of $\mathrm{As}(\mathrm{V})$ or $\mathrm{As}(\mathrm{III})$ were shaken at $150 \mathrm{r} / \mathrm{min}$ and $25^{\circ} \mathrm{C}$ for $16 \mathrm{hr}$. During the adsorption, the $\mathrm{pH}$ of all solutions was adjusted to $7.0 \pm 0.1$ at prescribed time intervals using $\mathrm{HCl}$ and $\mathrm{NaOH}$ solutions. Then the mixtures were centrifuged at $8000 \mathrm{r} / \mathrm{min}$ for $15 \mathrm{~min}$. The supernatants were taken and passed through a $0.22-\mu \mathrm{m}$ membrane filter. The concentrations of $\mathrm{As}(\mathrm{V})$ and $\mathrm{As}(\mathrm{III})$ were analyzed using ICP-MS.

In order to determine the adsorption isotherm of arsenic onto surfactant-coated $\mathrm{FH}$, before the arsenic adsorption experiment, surfactants were adsorbed onto $\mathrm{FH}$ by shaking $40 \mathrm{~mL}$ mixtures containing $0.1 \mathrm{~g} / \mathrm{L} \mathrm{FH}$ and $50 \mathrm{mg} / \mathrm{L}$ SDBS or Triton X-100 for $16 \mathrm{hr}$. Then the mixtures were centrifuged at $8000 \mathrm{r} / \mathrm{min}$ for $15 \mathrm{~min}$ and the supernatant was removed. A series of arsenic solutions with different concentrations were added into the tubes, and shaken at $150 \mathrm{r} / \mathrm{min}$ and $25^{\circ} \mathrm{C}$ for $16 \mathrm{hr}$. The $\mathrm{pH}$ of the suspensions was adjusted and maintained at $7.0 \pm 0.1$ during the adsorption experiments using $\mathrm{HCl}$ and $\mathrm{NaOH}$ solutions. Then the mixtures were centrifuged at $8000 \mathrm{r} / \mathrm{min}$ for $15 \mathrm{~min}$ and the arsenic concentration was measured using ICP-MS with proper dilution.

\subsection{Influence of surfactants on arsenic adsorption kinetics onto $\mathrm{FH}$}

To study the effects of surfactants at different concentrations on arsenic adsorption kinetics onto $\mathrm{FH}, 500 \mu \mathrm{g} / \mathrm{L} \mathrm{As}(\mathrm{V})$ or As(III) was mixed with SDBS or Triton X-100 of prescribed concentrations in 500-mL bottles, respectively. The dosage of $\mathrm{FH}$ was $0.01 \mathrm{~g} / \mathrm{L}$. All solutions were uniformly stirred with magnetic stirrers. The $\mathrm{pH}$ of all solutions was maintained at $7.0 \pm 0.1$ with $\mathrm{HCl}$ or $\mathrm{NaOH}$ solutions during the adsorption experiments. For As(III), the adsorption experiments were conducted in the dark under $\mathrm{N}_{2}$ atmosphere to avoid oxidation and photolysis. During the experiments, $1.0 \mathrm{~mL}$ aliquots were taken from each bottle at prescribed time intervals and centrifuged at 10,000 r/min for $5 \mathrm{~min}$, then the supernatant was taken and filtered through a $0.22-\mu \mathrm{m}$ membrane filter and stored at $4^{\circ} \mathrm{C}$ in the dark for arsenic concentration analysis.

The adsorption kinetics of arsenic onto surfactant-coated $\mathrm{FH}$ was also investigated. In $50-\mathrm{mL}$ centrifuge tubes, $0.5 \mathrm{~mL}$ FH suspension was first incubated with $49.5 \mathrm{~mL} 50 \mathrm{mg} / \mathrm{L}$ SDBS or Triton X-100 for $16 \mathrm{hr}$ under $150 \mathrm{r} / \mathrm{min}$. Then the suspension was transferred into a $500-\mathrm{mL}$ bottle containing $450 \mathrm{~mL} \mathrm{As(V)} \mathrm{or} \mathrm{As(III)} \mathrm{solution,} \mathrm{achieving} \mathrm{an} \mathrm{arsenic} \mathrm{con-}$ centration of $500 \mu \mathrm{g} / \mathrm{L}$. Thus the concentration of surfactant was less than $5 \mathrm{mg} / \mathrm{L}$. The $\mathrm{pH}$ of all solutions was maintained at $7.0 \pm 0.1$ during the experiment. At each prescribed time interval, $1.0 \mathrm{~mL}$ of solution was taken from each bottle and centrifuged at 10,000 r/min for $5 \mathrm{~min}$, then the supernatant was taken and filtered through a $0.22-\mu \mathrm{m}$ membrane filter and stored at $4^{\circ} \mathrm{C}$ in the dark for arsenic concentration analysis.

\subsection{Breakthrough of arsenic in the presence and pre-adsorption of SDBS}

Columns used in this study were of $3.0 \mathrm{~cm}$ internal diameter and $12.0 \mathrm{~cm}$ length. Each column was uniformly packed with $110.0 \mathrm{~g}$ FH-sand and equilibrated by an upward flow of de-ionized water for $48 \mathrm{hr}$ before the column investigation. The density of FH-sand was $2.5 \mathrm{~g} / \mathrm{cm}^{3}$ and the porosity of the packed columns was 0.48 . The influent rate was maintained at $0.12 \mathrm{~cm} / \mathrm{min}$ throughout the experiments. All As(III) flow-through experiments were conducted in the dark and under $\mathrm{N}_{2}$ atmosphere.

To study the transport of arsenic in the presence of SDBS in flow-through columns, comparison of arsenic breakthrough from columns with influx of $500 \mu \mathrm{g} / \mathrm{L}$ arsenic and of $500 \mu \mathrm{g} / \mathrm{L}$ arsenic with the coexistence of $30 \mathrm{mg} / \mathrm{L}$ SDBS was made. These solutions were pumped into the columns in an up-flow mode. The column adsorption experiments were carried out for $500 \mathrm{hr}$ (corresponding to 568.2 pore volumes (PV)) until the arsenic concentration in the effluent achieved a stable value. About $2.5 \mathrm{~mL}$ effluent was periodically taken from each column and centrifuged at 10,000 r/min for $5 \mathrm{~min}$, then the supernatant was filtered through a $0.22-\mu \mathrm{m}$ membrane filter and stored at $4^{\circ} \mathrm{C}$ in the dark for analysis. The breakthrough curves were acquired by recording the concentrations as a function of time.

To investigate arsenic transport through FH-sand coated with SDBS, a solution of $500 \mathrm{mg} / \mathrm{L}$ SDBS was constantly introduced into the $\mathrm{FH}$-sand column for $96 \mathrm{hr}$. Then a solution of $500 \mu \mathrm{g} / \mathrm{L} \mathrm{As}(\mathrm{V})$ or As(III) was introduced into the column to achieve a stable arsenic concentration in the effluent. At prescribed time intervals, $2.5 \mathrm{~mL}$ effluent was taken and centrifuged at $10,000 \mathrm{r} / \mathrm{min}$ for $5 \mathrm{~min}$, then the supernatant was filtered through a $0.22-\mu \mathrm{m}$ membrane filter and stored at $4^{\circ} \mathrm{C}$ in the dark for analysis.

\subsection{Mobilization of arsenic from FH by surfactants}

FH samples with different loading amounts of arsenic were acquired from the batch experiments. Then mobilization of arsenic from $\mathrm{FH}$ by surfactants was investigated in $40 \mathrm{~mL}$ $50 \mathrm{mg} / \mathrm{L}$ SDBS or Triton X-100 solutions. In such an experimental system, a relatively high surfactant concentration was chosen based on the great retention amount of arsenic onto FH compared to that on natural sediments. After shaking at $150 \mathrm{r} / \mathrm{min}$ for $16 \mathrm{hr}$ and centrifuging at $8000 \mathrm{r} / \mathrm{min}$ for $15 \mathrm{~min}$, the equilibrium concentration of arsenic in the supernatant was measured using ICP-MS.

\subsection{Mobilization of arsenic from columns by SDBS}

To study arsenic release from arsenic-loaded FH-sand, $500 \mu \mathrm{g} / \mathrm{L}$ $\mathrm{As}(\mathrm{V})$ and As(III) solutions were individually introduced to FH-sand columns until the arsenic concentration in the effluent reached $95 \%$ of the influx concentration. Then a solution of $30 \mathrm{mg} / \mathrm{L}$ SDBS was continuously pumped into the columns for $144 \mathrm{hr}$. The effluent from the column was collected and samples were periodically taken from the collected solution. The ratio of the cumulative released amount of arsenic to the sorption amount was calculated and plotted as a function of time. 


\subsection{Zeta potential measurement}

The Zeta potential of the $\mathrm{FH}$ particles in suspensions was determined using a ZetaSizer 3000 instrument (Malvern, UK). Suspensions of $0.1 \mathrm{~g} / \mathrm{L} \mathrm{FH}, 0.1 \mathrm{~g} / \mathrm{L} \mathrm{FH}$ with $30 \mathrm{mg} / \mathrm{L}$ SDBS or Triton X-100 were prepared. The $\mathrm{pH}$ of each batch of suspensions was adjusted to values ranging from 4 to 9 . After shaking for $16 \mathrm{hr}$, the final $\mathrm{pH}$ and Zeta potential values of all suspensions were measured.

\section{Results and discussion}

\subsection{Zeta potential measurement}

Zeta potential has been widely applied to characterize potential effects between particle surfaces and water. In this study, the adsorption of surfactants on FH significantly affected arsenic adsorption and transport behavior. As shown in Fig. 1, the isoelectric point was 7.2. The adsorption of SDBS significantly increased the negative charge on the $\mathrm{FH}$ surface. When the $\mathrm{pH}$ was 7.0, the adsorption of SDBS caused the surface charge to decrease from -1.49 to $-39.6 \mathrm{mV}$. This was an important factor contributing to the inhibition of arsenic adsorption, especially the adsorption of $\mathrm{As}(\mathrm{V})$, which mainly existed as anionic $\mathrm{HAsO}_{4}^{2-}$ and $\mathrm{H}_{2} \mathrm{AsO}_{4}^{-}$under the experimental $\mathrm{pH}$ condition of 7.0. For the nonionic Triton $\mathrm{X}-100$, its adsorption onto $\mathrm{FH}$ had little effect on the surface charge, which indicated that there should be no significant electrostatic repulsion between Triton $\mathrm{X}-100$ and arsenic species.

\subsection{Influence of surfactants on arsenic adsorption isotherm onto $\mathrm{FH}$}

2.2.1. Adsorption isotherm of arsenic in the presence of surfactants

As shown in Fig. 2a and b, adsorption isotherms of $\mathrm{As}(\mathrm{V})$ and As(III) were notably influenced by the coexistence of $50 \mathrm{mg} / \mathrm{L}$ SDBS or Triton X-100 compared to the systems without surfactants. The effects on the adsorption isotherms were mainly reflected in decreases in the equilibrium adsorbed amounts of $\mathrm{As}(\mathrm{V})$ and $\mathrm{As}(\mathrm{III})$ under the influence of SDBS or

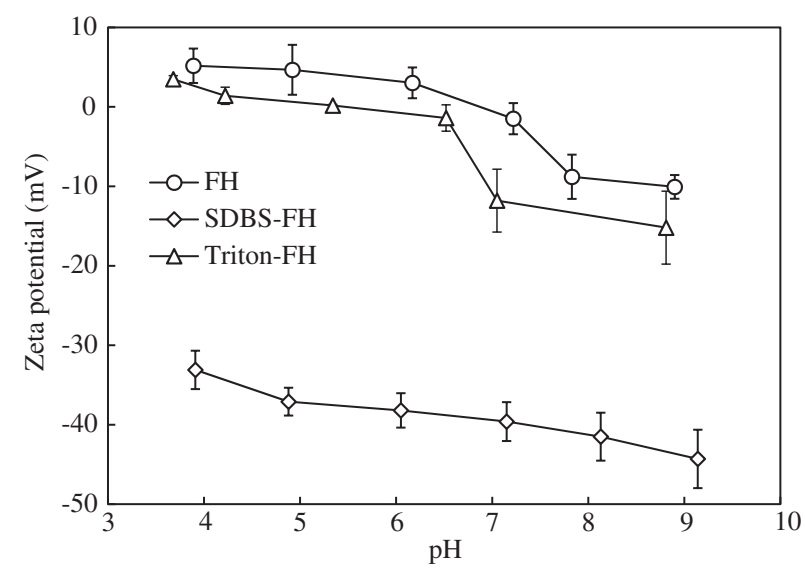

Fig. 1 - Zeta potential of FH (ferrihydrite) with or without coating by surfactants.
Triton X-100. In addition, the experimental data was best fitted with the Langmuir model, presented as:

$q_{e}=q_{\max } \frac{k_{\mathrm{L}} C_{e}}{1+k_{\mathrm{L}} C_{e}}$

where $q_{\mathrm{e}}(\mathrm{mg} / \mathrm{g})$ is the equilibrium adsorbed amount, $q_{\max }$ $(\mathrm{mg} / \mathrm{g})$ is the maximum adsorbed amount, and $k_{\mathrm{L}}(\mathrm{L} / \mathrm{mg})$ is the Langmuir equilibrium constant.

Details of the fitting results are given in Appendix Fig. S2. Specifically, as shown in Table 2, without the effects of surfactants, the calculated maximum adsorbed amount of $\mathrm{As}(\mathrm{V})$ and $\mathrm{As}$ (III) on FH was 40.5 and $83.3 \mathrm{mg} / \mathrm{g}$, respectively. In the presence of $50 \mathrm{mg} / \mathrm{L}$ SDBS and Triton X-100, the maximum adsorbed amount of $\mathrm{As}(\mathrm{V})$ decreased to 38.3 and $38.5 \mathrm{mg} / \mathrm{g}$, while that of As(III) decreased to 77.5 and $75.8 \mathrm{mg} / \mathrm{g}$. In addition, according to the fitting results, the influence of SDBS on As(V) adsorption was greater, while Triton X-100 showed greater effects on the adsorption of As(III) onto FH. Under the experimental $\mathrm{pH}$ conditions, $\mathrm{As}(\mathrm{V})$ existed mainly as anionic $\mathrm{HAsO}_{4}^{2-}$, while $\mathrm{As}$ (III) existed as neutral $\mathrm{H}_{3} \mathrm{AsO}_{3}$ (Smedley et al., 2005). According to the Zeta potential analysis, when the $\mathrm{pH}$ was approximately 7.0, the adsorption of SDBS caused a FH surface charge decrease from $-1.49 \mathrm{mV}$ to $-39.6 \mathrm{mV}$, indicating that there could be electrostatic repulsion between SDBS and the negatively charged As(V). The influence of SDBS on As(III) retention and the effects of Triton X-100 on $\mathrm{As}(\mathrm{V})$ and $\mathrm{As}$ (III) retention were mainly due to the occupation of adsorption sites on FH particles.

2.2.2. Adsorption isotherm of arsenic onto surfactant-coated FH Adsorption isotherms of arsenic onto surfactant-coated $\mathrm{FH}$ are shown in Fig. $2 \mathrm{c}$ and d. It was found that the pre-coating of SDBS and Triton X-100 slightly reduced the adsorbed amount of $\mathrm{As}(\mathrm{V})$, but had less effect on the amount of adsorbed As(III). Similarly, Langmuir fitting of the experimental data is also given in Table 2. According to the fitting results, the adsorbed amounts of $\mathrm{As}(\mathrm{V})$ and $\mathrm{As}(\mathrm{III})$ onto SDBS-coated FH decreased to 36.8 and $75.8 \mathrm{mg} / \mathrm{g}$, respectively. For Triton X-100-coated $\mathrm{FH}$, the adsorbed amounts of $\mathrm{As}(\mathrm{V})$ and $\mathrm{As}(\mathrm{III})$ decreased to 37.7 and $77.5 \mathrm{mg} / \mathrm{g}$, respectively. Compared to the coexisting condition, pre-coating of surfactants onto $\mathrm{FH}$ had greater effects on arsenic adsorption isotherms.

\subsection{Influence of surfactants on arsenic adsorption kinetics}

\subsubsection{Adsorption kinetics of arsenic coexisting with SDBS or} Triton X-100

Studies have shown that the adsorption kinetics of arsenic onto FH mainly includes three processes: external diffusion, internal diffusion and surface adsorption (Radu et al., 2005; Zhang and Selim, 2005; Zhao et al., 2011). Therefore, the presence of surfactants could affect arsenic adsorption behavior by affecting these three processes. As shown in Fig. $3 a$ and $b$, adsorption kinetics of $\mathrm{As}(\mathrm{V})$ and $\mathrm{As}(\mathrm{III})$ were slightly affected in the presence of SDBS and Triton X-100, and the extent of the effects increased with the increase of surfactant concentrations. The kinetics represented a two-stage process, in which adsorption equilibrium of $\mathrm{As}(\mathrm{V})$ and $\mathrm{As}(\mathrm{III})$ was achieved at 60 and $150 \mathrm{~min}$, respectively. This indicated that the presence of SDBS and Triton X-100 had little effect on the 

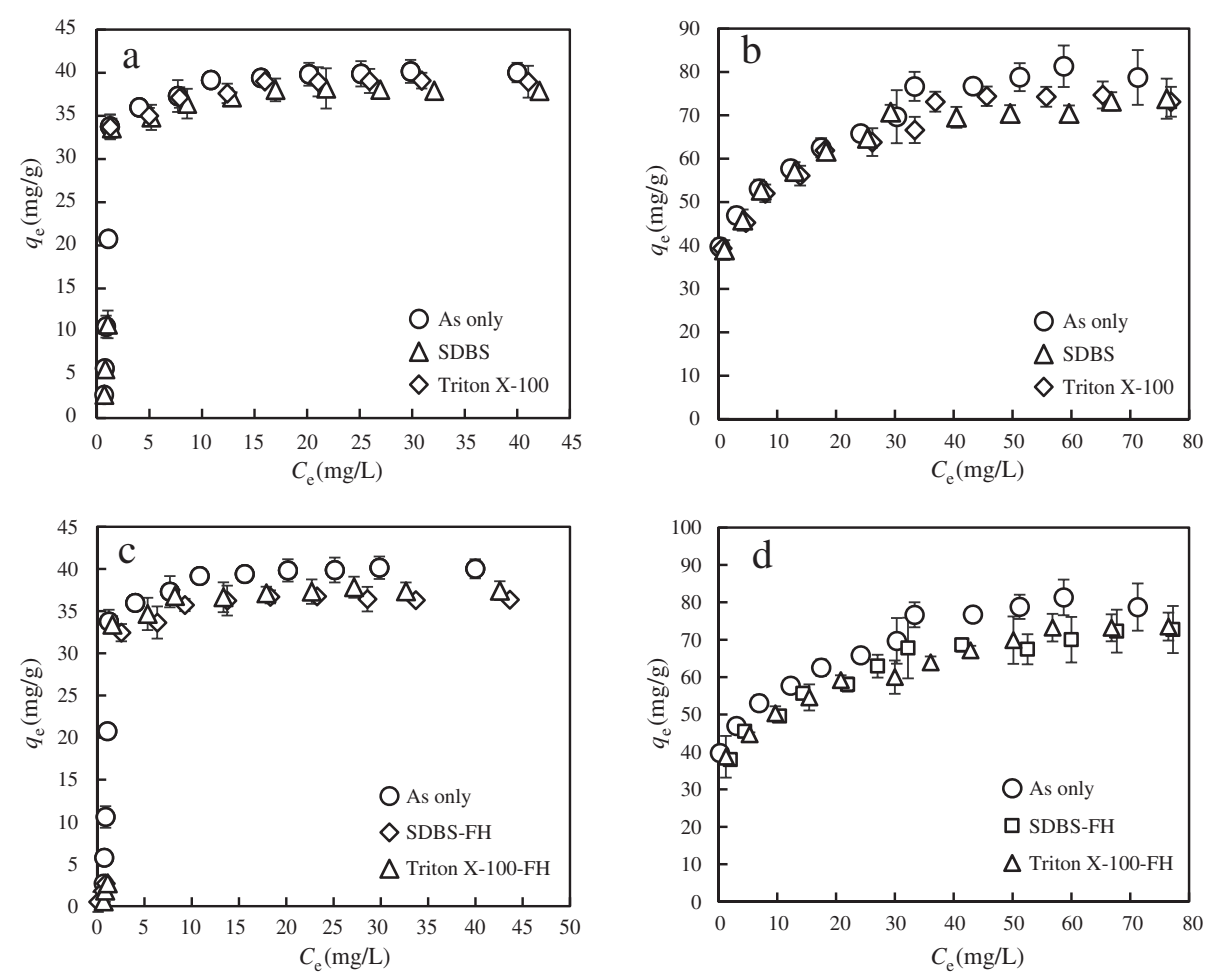

Fig. 2 - Adsorption isotherm of $\mathrm{As}(\mathrm{V})$ (a) and $\mathrm{As}(\mathrm{III})$ (b) onto FH in the presence of SDBS or Triton X-100 at pH 7.0. Adsorption isotherm of $\mathrm{As}(\mathrm{V})$ (c) and $\mathrm{As}(\mathrm{III})(\mathrm{d})$ onto FH coated with SDBS or Triton X-100 at pH 7.0.

time for achieving equilibrium. Thus, to further compare arsenic adsorption kinetics with or without the presence of surfactants, the adsorption kinetics was fitted to the Pseudo-second order kinetic model, presented as:

$\frac{d q_{t}}{d t}=k_{2}\left(q_{e}-q_{t}\right)^{2}$.

$q_{t}(\mathrm{mg} / \mathrm{g})$ is the adsorbed amount of arsenic at time $t$, presented as:

$q_{t}=\frac{C_{0}-C_{t}}{m} V$

where $q_{\mathrm{e}}(\mathrm{mg} / \mathrm{g})$ is the equilibrium adsorption amount, $k_{2}(\mathrm{~g} /$ (mg.min)) is the second order adsorption kinetic constant, $m(g)$ is the dosage of $\mathrm{FH}$, and $\mathrm{C}_{0}(\mathrm{mg} / \mathrm{L})$ and $C_{\mathrm{t}}(\mathrm{mg} / \mathrm{L})$ represent the initial arsenic concentration and concentration at time $t$, respectively.
Details of the adsorption kinetic fitting are given in Appendix A Fig. S3. According to the fitting results given in Table 3, the presence of SDBS and Triton X-100 mainly affected arsenic adsorption kinetics in two aspects: equilibrium adsorbed amount and adsorption rate. The presence of SDBS, at 10 and $50 \mathrm{mg} / \mathrm{L}$, reduced the equilibrium adsorbed amount of both $\mathrm{As}(\mathrm{V})$ and $\mathrm{As}(\mathrm{III})$ on FH. This could mainly be attributed to the occupation of adsorption sites on the $\mathrm{FH}$ surface by the adsorption of SDBS. The effects on the adsorption rate of arsenic varied with the concentration of SDBS. Specifically, when the suspensions contained $10 \mathrm{mg} / \mathrm{L}$ SDBS, the second-order adsorption kinetic constants $k_{2}$ of $\mathrm{As}(\mathrm{V})$ and As(III) increased from 7.4 and 2.6 to 9.9 and 3.0, respectively, which indicated that SDBS at $10 \mathrm{mg} / \mathrm{L}$ could to some extent promote the adsorption rate. When the concentration of SDBS increased to $50 \mathrm{mg} / \mathrm{L}$, the adsorption kinetic

Table 2 - Langmuir fitting for As adsorption onto FH coexisting with surfactant and As adsorption onto surfactant-coated FH.

\begin{tabular}{|c|c|c|c|c|c|c|c|c|}
\hline \multicolumn{5}{|c|}{ Adsorption of As coexisting with surfactants } & \multicolumn{4}{|c|}{ Adsorption of As on surfactant coated FH } \\
\hline & Surfactant & $\begin{array}{c}k_{\mathrm{L}} \\
(\mathrm{L} / \mathrm{mg})\end{array}$ & $\begin{array}{c}q_{\max } \\
(\mathrm{mg} / \mathrm{g})\end{array}$ & $R^{2}$ & $\mathrm{FH}$ & $\begin{array}{c}k_{\mathrm{L}} \\
(\mathrm{L} / \mathrm{mg})\end{array}$ & $\begin{array}{c}q_{\max } \\
(\mathrm{mg} / \mathrm{g})\end{array}$ & $R^{2}$ \\
\hline \multirow{3}{*}{$\operatorname{As}(\mathrm{V})$} & Without surfactant & 2.3 & 40.5 & 0.999 & Bare FH & 2.3 & 40.5 & 0.999 \\
\hline & SDBS & 3.2 & 38.3 & 0.999 & SDBS-FH & 3.7 & 36.8 & 0.999 \\
\hline & Triton X-100 & 2.7 & 38.5 & 0.998 & Triton X-100-FH & 3.4 & 37.7 & 0.999 \\
\hline \multirow[t]{3}{*}{ As(III) } & Without surfactant & 0.3 & 83.3 & 0.993 & Bare FH & 0.3 & 83.3 & 0.993 \\
\hline & SDBS & 0.3 & 77.5 & 0.995 & SDBS-FH & 0.2 & 75.8 & 0.997 \\
\hline & Triton X-100 & 0.3 & 75.8 & 0.998 & Triton X-100-FH & 0.2 & 77.5 & 0.998 \\
\hline
\end{tabular}



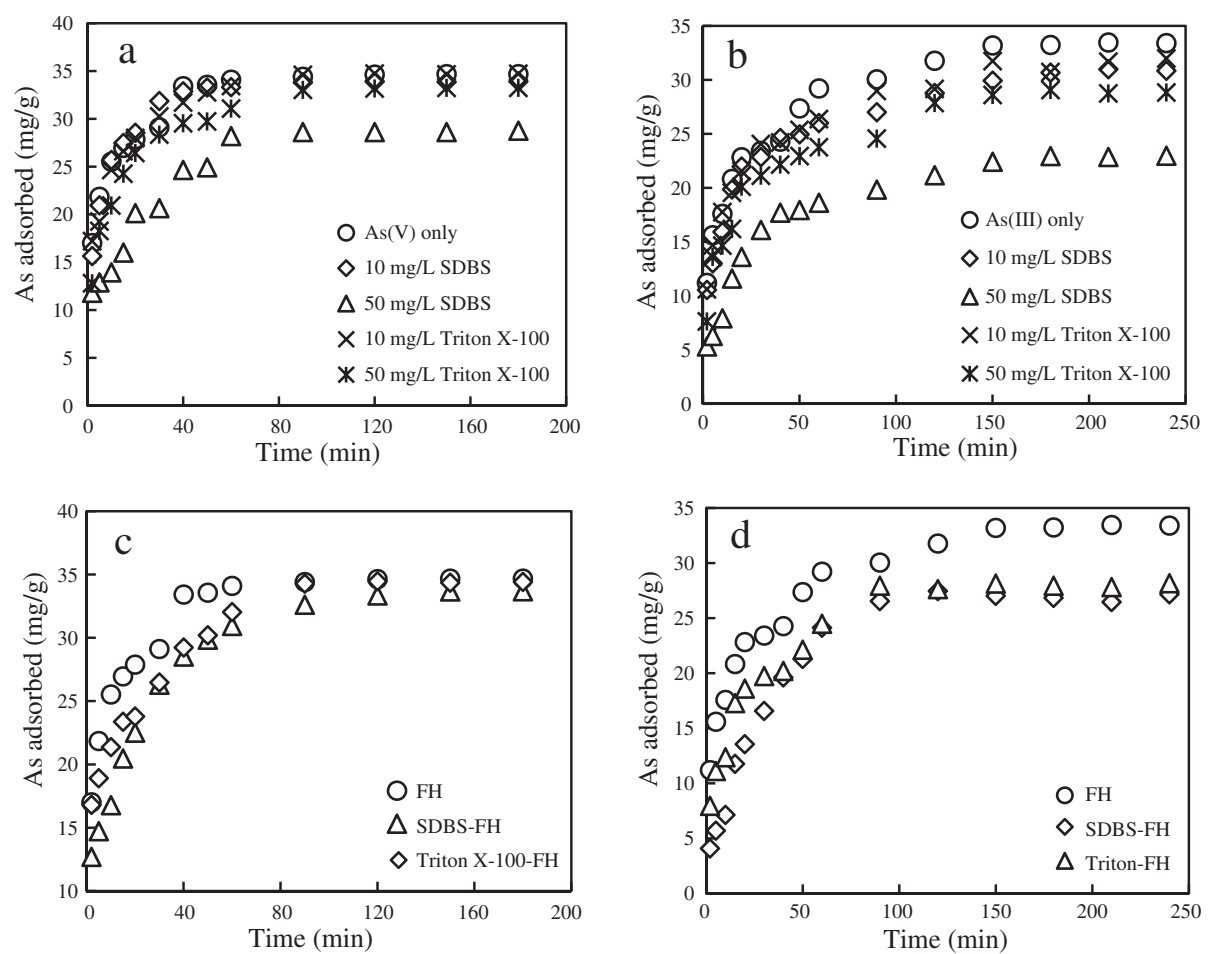

Fig. 3 - Adsorption kinetics of As(V) (a) and As(III) (b) on FH in the presence of SDBS or Triton X-100 at different concentrations at pH 7.0. Adsorption kinetics of $\mathrm{As}(\mathrm{V})$ (c) and As(III) (d) on FH coated with SDBS and Triton X-100 at pH 7.0.

constants of $\mathrm{As}(\mathrm{V})$ and $\mathrm{As}(\mathrm{III})$ decreased to 3.6 and 2.5, respectively. The adsorption of SDBS could reduce the interfacial tension between $\mathrm{FH}$ and water as well as enhance the wettability of the FH surface, promoting the external diffusion of arsenic to the FH surface (Sastry and Dave, 1999; Thibaut et al., 2000; Wang and Kwak, 1999; Yang et al., 2007, 2010). The nonionic surfactant Triton $X-100$ exerted different impacts on the adsorption kinetics of $\mathrm{As}(\mathrm{V})$ and $\mathrm{As}(\mathrm{III})$. At both 10 and $50 \mathrm{mg} / \mathrm{L}$, Triton X-100 caused a decrease of both equilibrium adsorption amount and second-order adsorption kinetic constant of $\mathrm{As}(\mathrm{V})$. As for $\mathrm{As}(\mathrm{III})$, the coexistence of 10 and $50 \mathrm{mg} / \mathrm{L}$ Triton X-100 reduced its equilibrium adsorbed amounts while enhancing the adsorption rate.

\subsubsection{Adsorption kinetics of arsenic onto surfactant-coated FH}

In the natural environment, wastewater containing arsenic could be discharged into surfactant-loaded soil and sediment. Thus, the pre-coating of surfactants could potentially have impacts on arsenic retention, enhancing its mobility in the environment. Similarly, the experimental data was also fitted to the Pseudo-second order kinetic model. According to Fig. 3c and $\mathrm{d}$ and Table 3, the adsorption kinetics of $\mathrm{As}(\mathrm{V})$ and $\mathrm{As}(\mathrm{III})$ on surfactant-coated $\mathrm{FH}$ changed compared to that on bare $\mathrm{FH}$. The adsorption of $\mathrm{As}(\mathrm{V})$ was able to reach equilibrium at $60 \mathrm{~min}$ and the equilibrium adsorption amount did not obviously decrease. The pre-coating of SDBS and Triton $\mathrm{X}-100$ caused a decrease of the adsorption kinetic constant of $\mathrm{As}(\mathrm{V})$ from 7.4 to 3.1 and 3.9, respectively. This was attributed to the electrostatic repulsion between adsorbed SDBS and As(V) anions. As for As(III), adsorption equilibrium on surfactant-coated $\mathrm{FH}$ was achieved at $90 \mathrm{~min}$, which was

60 min faster than that on bare FH. In addition, with pre-coating of SDBS and Triton X-100, the adsorption kinetics of As(III) increased from 2.6 to 2.8 and 2.9, respectively. However, the equilibrium adsorption amount of As(III) decreased from $35.0 \mathrm{mg} / \mathrm{g}$ to 29.9 and $29.7 \mathrm{mg} / \mathrm{g}$, respectively.

Table 3-Pseudo-second order kinetic fitting of As adsorption in the presence of surfactant and onto surfactant-coated FH.

Batch

$$
k_{2}(g /(\mathrm{mg} \cdot \min ))
$$$$
q_{\mathrm{e}}
$$$$
(\mathrm{mg} / \mathrm{g})
$$

$R^{2}$

As adsorption in the presence of SDBS or Triton X-100

$\mathrm{As}(\mathrm{V})$

$10 \mathrm{mg} / \mathrm{L}$ SDBS

$50 \mathrm{mg} / \mathrm{L}$ SDBS

$10 \mathrm{mg} / \mathrm{L}$ Triton X-100

50 mg/L Triton X-100

As(III)

$10 \mathrm{mg} / \mathrm{L}$ SDBS

$50 \mathrm{mg} / \mathrm{L}$ SDBS

$10 \mathrm{mg} / \mathrm{L}$ Triton X-100

50 mg/L Triton X-100

7.4

9.9

3.6

6.5

5.1

2.6

3.0

2.5

2.8

2.8

35.6

34.6

30.5

35.7

34.5

35.0

32.05

24.6

33.0

30.3

0.999

0.999

0.997

0.999

0.999

0.998

0.998

0.998

0.997

0.997

As adsorption on FH coated with SDBS and Triton X-100

$\begin{array}{lllll}\mathrm{As}(\mathrm{V}) & \mathrm{FH} & 7.4 & 35.6 & 0.999\end{array}$ $\begin{array}{llll}\text { SDBS-FH } & 3.1 & 35.6 & 0.998 \\ \text { Titon X-100-FH } & 3.9 & 36.0 & 0.991\end{array}$ $\begin{array}{llll}\text { Triton X-100-FH } & 3.9 & 36.0 & 0.991\end{array}$

$\begin{array}{lllll}\text { As(III) } & \text { FH } & 2.6 & 35.0 & 0.998\end{array}$

$\begin{array}{llll}\text { SDBS-FH } & 2.8 & 29.9 & 0.994\end{array}$

$\begin{array}{llll}\text { Triton X-100-FH } & 2.9 & 29.7 & 0.997\end{array}$

FH: ferrihydrite; SDBS: sodium dodecyl benzene sulfonate. 

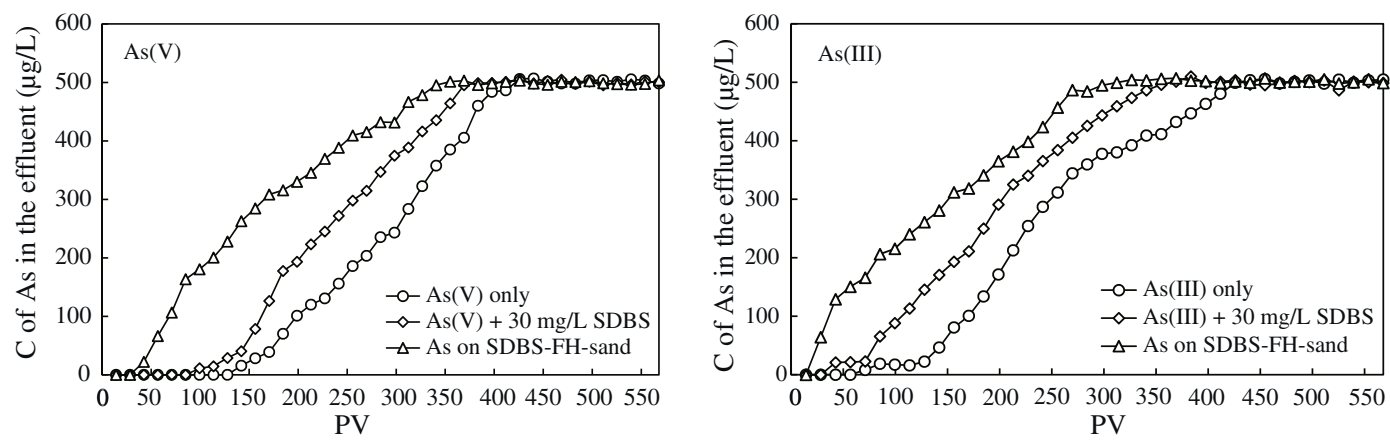

Fig. 4 - Breakthrough curves of $\mathrm{As}(\mathrm{V})$ and $\mathrm{As}(\mathrm{III})$ in the presence of SDBS at pH 7.0.

\subsection{Transport behavior of arsenic in the presence of SDBS}

Transport of arsenic through sediment is an important process governing arsenic concentrations in groundwater (Sharma et al., 2011). Based on the batch tests discussed above, surfactants had the potential to affect arsenic adsorption onto FH by competing for adsorption sites and electrostatic repulsion. Thus, surfactants could also influence the transport behavior in flow-through systems. The column experiments were conducted concerning two aspects: (1) transport of arsenic through FH-sand column with the coexistence of SDBS; and (2) arsenic transport through SDBS coated FH-sand. Comparison between the breakthrough of arsenic with and without the presence of SDBS was made to quantify the transport behavior of arsenic under the effect of SDBS. The flow-through experiment was run for $568 \mathrm{PV}$. As shown in Fig. 4, As(V) and As(III) had similar transport behavior in FH-sand columns. The PV when the concentration of arsenic in the effluent reached $50 \%$ of the influx concentration was employed to compare the breakthrough of arsenic in the absence or presence of SDBS (Sharma et al., 2011). Thus, breakthrough of As(III) occurred at 227.2 PV, more rapidly than As(V) breakthrough, which occurred at 298.2 PV, indicating the greater mobility of As(III). In the presence of SDBS, breakthrough of $\mathrm{As}(\mathrm{V})$ and $\mathrm{As}(\mathrm{III})$ occurred at 227.2 and 184.6 PV, 23.8 and $14.3 \%$ faster than that in SDBS-free systems, respectively. Since the concentration of arsenic (C) in the effluent could be represented as a function of time ( $t$ ), the cumulative adsorption amount of arsenic $(Q)$ throughout the process of breakthrough could be calculated from the start of influx to the achievement of stable concentration in the effluent, presented as the following formulation:

$\mathrm{Q}=\mathrm{C}_{0} \cdot \mathrm{t}_{e} \cdot v-\int_{\mathrm{t}_{0}}^{\mathrm{t}_{e}} \mathrm{C}(\mathrm{T}) \cdot v \cdot d \mathrm{t}$

where $t_{0}(h r)$, and $t_{e}(h r)$ are the times when arsenic concentration in the effluent became larger than zero and reached stability, which could be acquired from the breakthrough curves; $C_{0}$ is the influx concentration of arsenic (500 $\mu \mathrm{g}$ / $\mathrm{L}$ in this study); and $\mathrm{v}$ is the influent rate $(50 \mathrm{~mL} / \mathrm{hr}$ in this study).

The integral was calculated using Origin software. The maximum cumulative retention amount of $\mathrm{As}(\mathrm{V})$ and $\mathrm{As}$ (III) on FH-sand during the flow-through process was 56.8 and
$49.8 \mathrm{mg} / \mathrm{kg}$. Under the influence of SDBS, the cumulative adsorbed amount of $\mathrm{As}(\mathrm{V})$ and $\mathrm{As}(\mathrm{III})$ was 47.0 and $36.8 \mathrm{mg} / \mathrm{kg}$, which was $17.2 \%$ and $26.0 \%$ less than that in the corresponding SDBS-free columns, respectively. In summary, the presence of SDBS had great potential to enhance arsenic breakthrough and reduce arsenic retention, promoting its transport through sediment.

Similarly, this study also investigated arsenic transport through FH-sand coated with SDBS. It was indicated that compared to the systems with coexisting SDBS, the pre-coating of SDBS caused more significant impacts on arsenic transport. The breakthrough of $\mathrm{As}(\mathrm{V})$ and $\mathrm{As}(\mathrm{III})$ occurred at 142.0 and 127.8 PV, which was $52.4 \%$ and $43.8 \%$ more rapid than in columns packed with bare FH-sand. In addition, the calculated cumulative adsorbed amount of $\mathrm{As}(\mathrm{V})$ and $\mathrm{As}(\mathrm{III})$ on SDBS-coated FH-sand was 31.5 and $21.2 \mathrm{mg} / \mathrm{kg}$, respectively, which was $44.5 \%$ and $57.3 \%$ less than the amount of arsenic retained by the bare FH-sand. The pre-coating of SDBS on FH-sand resulted in an obvious inhibition of arsenic retention, indicating that when passing through sediment coated with SDBS in the environment, arsenic mobility would be greatly enhanced.

\subsection{Mobilization of arsenic from $\mathrm{FH}$ and $\mathrm{FH}$-sand by surfactants}

Surfactants have been widely used in the enhanced remediation of pollution caused by organic matters and heavy metals (Edwards et al., 1991; Mulligan et al., 2001; Nivas et al., 1996; Tripathi and Brown, 2008; Zhao et al., 2006). Previous studies have shown that surfactants with a concentration higher than $10 \mathrm{CMC}$ (critical micelle concentration) had great potential in eluting arsenic from mine tailings. The eluting process was essentially a process of release of arsenic by surfactants (Mukhopadhyay et al., 2013; Wang and Mulligan, 2009a, 2009b). Thus, the present study investigated the possibility and efficiency of arsenic mobilization from $\mathrm{FH}$ and $\mathrm{FH}$-sand by surfactants in both batch tests and column experiments. In addition, the effect of the initial loading amount of arsenic on its mobilization by surfactants was also studied. As shown in Fig. 5, the release rate of $\mathrm{As}(\mathrm{V})$ by SDBS and Triton X-100 was $2.9 \%$ and $2.3 \%$, respectively. The concentrations of $\mathrm{As}(\mathrm{V})$ in SDBS and Triton X-100 system reached 1.2 and $0.9 \mathrm{mg} / \mathrm{L}$, respectively. Because of its greater mobility, the maximum release rate of As(III) by SDBS and Triton X-100 was $7.3 \%$ and $5.9 \%$, respectively. Meanwhile, the equilibrium concentrations in SDBS and 

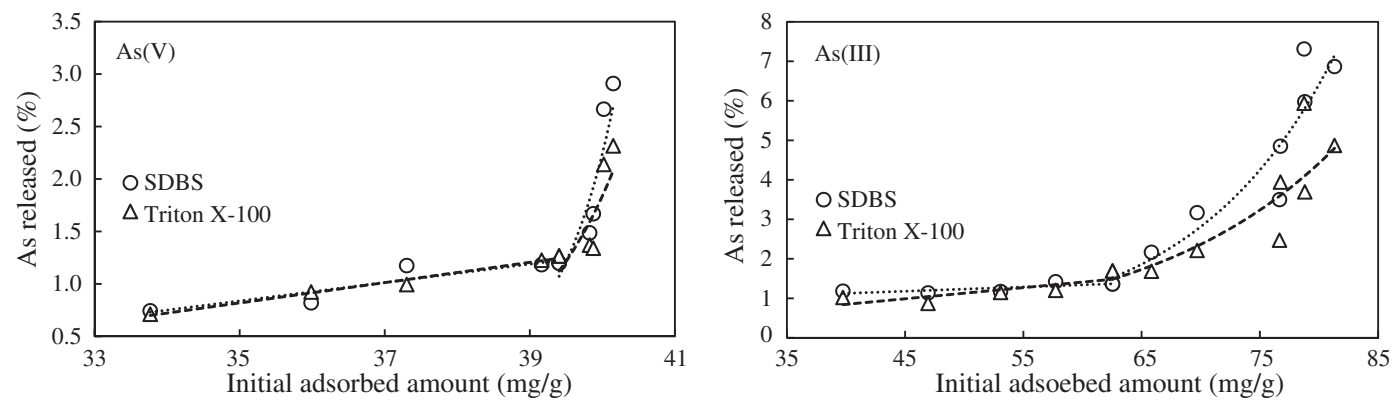

Fig. 5 - Influence of initial adsorbed amount of As on its mobilization by SDBS and Triton X-100.

Triton X-100 solution reached 5.8 and $4.7 \mathrm{mg} / \mathrm{L}$. The relatively low mobilization rates indicated that the fraction of arsenic mobilized from the FH surface was mainly the weakly associated fractions, and the mobilization could be mainly attributed to adsorption exchange by surfactants. In addition, the mobilization of arsenic by $50 \mathrm{mg} / \mathrm{L}$ SDBS and Triton X-100 increased with the increase of initial arsenic loading amount. To be specific, the release rate increased linearly with initial adsorbed amount when the initial adsorbed amount of $\mathrm{As}(\mathrm{V})$ and As(III) was lower than 38.9 and $57.7 \mathrm{mg} / \mathrm{g}$, corresponding to $97.0 \%$ and $79.5 \%$ of the maximum adsorption amount, respectively. As the initial adsorption amount increased, the release rate sharply increased. This indicated that the more serious arsenic pollution was, the more arsenic could be replaced by surfactants.

In the column experiments, $50 \mathrm{mg} / \mathrm{L}$ SDBS solution was continuously pumped into a column packed with arsenicloaded FH-sand. The effluents were collected and the cumulative released amounts of arsenic were calculated and recorded as a function of flushing time. As shown in Fig. 6, the amount of As(V) and As(III) mobilized by SDBS was significantly larger than that mobilized by water. During the mobilization process, more As(III) was replaced by the flow through of SDBS than As(V), which was consistent with the batch experiments indicating the greater mobility of $\mathrm{As}(\mathrm{III})$. There was up to $10.8 \%$ of $\mathrm{As}(\mathrm{V})$ and $36.0 \%$ of adsorbed As(III) cumulatively mobilized by the continuous influx of $30 \mathrm{mg} / \mathrm{L}$ SDBS for $144 \mathrm{hr}$. Compared to the slight release in batch experiments, continuous influx of SDBS solution showed greater efficiency in mobilizing arsenic.

\section{Conclusions}

The present study investigated arsenic retention, transport and release behavior in the presence of the anionic surfactant SDBS and nonionic surfactant Triton X-100. The results of this study showed that the presence of anionic SDBS and nonionic Triton X-100 could enhance the mobility of arsenic by reducing arsenic retention onto $\mathrm{FH}$, enhancing arsenic transport through $\mathrm{FH}$-sand columns and promoting arsenic mobilization from FH. Mechanisms by which surfactants influence arsenic behavior include electrostatic repulsion and occupation of adsorption sites.

\section{Acknowledgments}

This work was supported by the National Natural Science Foundation of China (No. 41273123) and the special fund from the State Key Joint Laboratory of Environment Simulation and Pollution Control (Research Center for Eco-environmental Sciences, Chinese Academy of Sciences) (No. 14Z02ESPCR).

\section{Appendix A. Supplementary data}

Supplementary data to this article can be found online at http://dx.doi.org/10.1016/j.jes.2015.12.007.
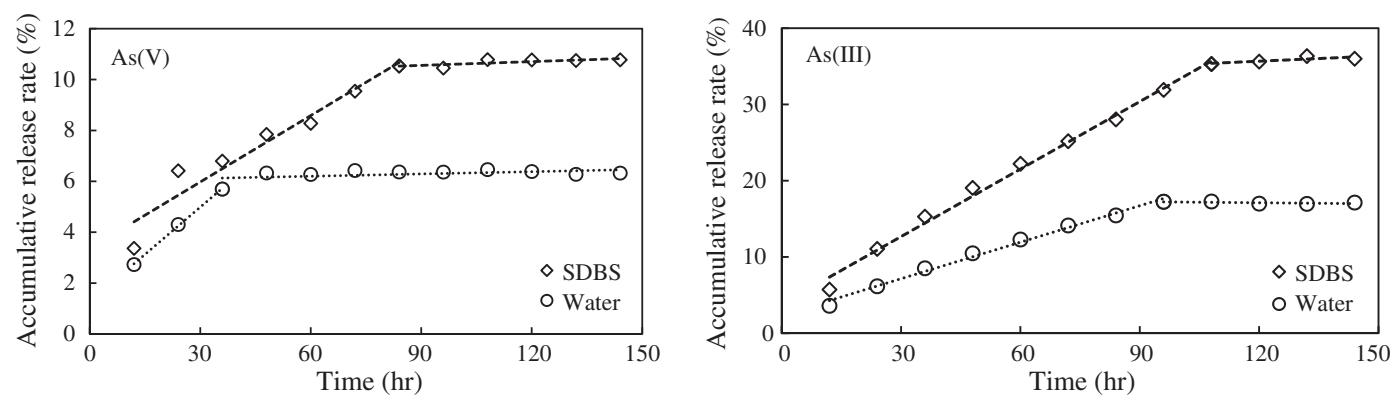

Fig. 6 - Release of $\mathrm{As}(\mathrm{V})$ and $\mathrm{As}(\mathrm{III})$ from columns by the influx of $50 \mathrm{mg} / \mathrm{L}$ SDBS. 


\section{R E F E R E N C E S}

Barringer, J.L., Reilly, P.A., Eberl, D.D., Blum, A.E., Bonin, J.L., Rosman, R., Hirst, B., Alebus, M., Cenno, K., Gorska, M., 2011. Arsenic in sediments, groundwater, and streamwater of a glauconitic Coastal Plain terrain, New Jersey, USA-Chemical "fingerprints" for geogenic and anthropogenic sources. Appl. Geochem. 26 (5), 763-776.

Céspedes, R., Lacorte, S., Ginebreda, A., Barceló, D., 2008. Occurrence and fate of alkylphenols and alkylphenol ethoxylates in sewage treatment plants and impact on receiving waters along the Ter River (Catalonia, NE Spain). Environ. Pollut. 153 (2), 384-392.

Clara, M., Scharf, S., Scheffknecht, C., Gans, O., 2007. Occurrence of selected surfactants in untreated and treated sewage. Water Res. 41 (19), 4339-4348.

de Wolf, W., Feijtel, T., 1998. Terrestrial risk assessment for linear alkyl benzene sulfonate (LAS) in sludge-amended soils. Chemosphere 36 (6), 1319-1343.

Dias, F.F., Allen, H.E., Guimaraes, J.R., Taddei, M.H.T., Nascimento, M.R., Guilherme, L.R.G., 2009. Environmental behavior of arsenic(III) and (V) in soils. J. Environ. Monit. 11 (7), 1412-1420.

Edwards, D.A., Luthy, R.G., Liu, Z., 1991. Solubilization of polycyclic aromatic hydrocarbons in micellar nonionic surfactant solutions. Environ. Sci. Technol. 25 (1), 127-133.

Fu, M., Li, Z., Gao, H., 2007. Distribution characteristics of nonylphenol in Jiaozhou Bay of Qingdao and its adjacent rivers. Chemosphere 69 (7), 1009-1016.

Garcia, M.G., Sracek, O., Fernandez, D.S., Hidalgo, M.D.V., 2007. Factors affecting arsenic concentration in groundwaters from Northwestern Chaco-Pampean Plain. Argent. Environ. Geol. 52 (7), 1261-1275.

Garcia-Sanchez, A., Alonso-Rojo, P., Santos-Frances, F., 2010. Distribution and mobility of arsenic in soils of a mining area (Western Spain). Sci. Total Environ. 408 (19), 4194-4201.

Guo, H.M., Wen, D.G., Liu, Z.Y., Jia, Y.F., Guo, Q., 2014. A review of high arsenic groundwater in Mainland and Taiwan, China: distribution, characteristics and geochemical processes. Appl. Geochem. 41, 196-217.

He, Y.T., Fitzmaurice, A.G., Bilgin, A., Choi, S., O’Day, P., Horst, J., Harrington, J., James Reisinger, H., Burris, D.R., Hering, J.G., 2010. Geochemical processes controlling arsenic mobility in groundwater: a case study of arsenic mobilization and natural attenuation. Appl. Geochem. 25 (1), 69-80.

Kloepper-Sams, P., Torfs, F., Feijtel, T., Gooch, J., 1996. Effects assessments for surfactants in sludge-amended soils: a literature review and perspectives for terrestrial risk assessment. Sci. Total Environ. 185 (1-3), 171-185.

Lara-Martín, P.A., Petrovic, M., Gómez-Parra, A., Barceló, D., González-Mazo, E., 2006. Presence of surfactants and their degradation intermediates in sediment cores and grabs from the Cadiz Bay area. Environ. Pollut. 144 (2), 483-491.

Lara-Martín, P.A., Gómez-Parra, A., González-Mazo, E., 2008. Sources, transport and reactivity of anionic and non-ionic surfactants in several aquatic ecosystems in SW Spain: a comparative study. Environ. Pollut. 156 (1), 36-45

Lara-Martin, P.A., Gomez-Parra, A., Gonzalez-Mazo, E., 2008. Reactivity and fate of synthetic surfactants in aquatic environments. Trac-Trend. Anal. Chem. 27 (8), 684-695.

Marcomini, A., Pojana, G., Sfriso, A., Alonso, J.M.Q., 2000. Behavior of anionic and nonionic surfactants and their persistent metabolites in the Venice lagoon. Italy. Environ. Toxicol. Chem. 19 (8), 2000-2007

Mukhopadhyay, S., Hashim, M.A., Sahu, J.N., Yusoff, I., Sen Gupta, B., 2013. Comparison of a plant based natural surfactant with
SDS for washing of As(V) from Fe rich soil. J. Environ. Sci. China 25 (11), 2247-2256.

Mulligan, C.N., Yong, R.N., Gibbs, B.F., 2001. Heavy metal removal from sediments by biosurfactants. J. Hazard. Mater. 85 (1-2), 111-125.

Nivas, B.T., Sabatini, D.A., Shiau, B.-J., Harwell, J.H., 1996. Surfactant enhanced remediation of subsurface chromium contamination. Water Res. 30 (3), 511-520.

Pan, G., Jia, C.X., Zhao, D.Y., You, C., Chen, H., Jiang, G.B., 2009. Effect of cationic and anionic surfactants on the sorption and desorption of perfluorooctane sulfonate (PFOS) on natural sediments. Environ. Pollut. 157 (1), 325-330.

Radloff, K.A., Cheng, Z.Q., Rahman, M.W., Ahmed, K.M., Mailloux, B.J., Juhl, A.R., Schlosser, P., van Geen, A., 2007. Mobilization of arsenic during one-year incubations of grey aquifer sands from Araihazar. Bangladesh Environ. Sci. Technol. 41 (10), 3639-3645.

Radu, T., Subacz, J.L., Phillippi, J.M., Barnett, M.O., 2005. Effects of dissolved carbonate on arsenic adsorption and mobility. Environ. Sci. Technol. 39 (20), 7875-7882.

Reza, A.H.M.S., Jean, J.S., Yang, H.J., Lee, M.K., Woodall, B., Liu, C.C., Lee, J.F., Luo, S.D., 2010. Occurrence of arsenic in core sediments and groundwater in the Chapai-Nawabganj District, northwestern Bangladesh. Water Res. 44 (6), 2021-2037.

Sastry, N.V., Dave, P.N., 1999. Adsorption behavior of surfactant-polyacrylamide mixtures with kaolin. J. Surfactant Deterg. 2 (4), 459-472.

Serfes, M., Spayd, S., Herman, G., 2003. Occurrence, sources, mobilization and transport of arsenic in the Newark Basin in New Jersey. Abstr. Pap. Am. Chem. Soc. 226, U584.

Shalaby, M.N., 2007. Behavior study of some commercial nonionic compounds in comparison with anionic surfactant. Chem. Eng. Commun. 194 (4), 464-476.

Sharma, P., Rolle, M., Kocar, B., Fendorf, S., Kappler, A., 2011. Influence of natural organic matter on As transport and retention. Environ. Sci. Technol. 45 (2), 546-553.

Smedley, P.L., Kinniburgh, D.G., Macdonald, D.M.J., Nicolli, H.B., Barros, A.J., Tullio, J.O., Pearce, J.M., Alonso, M.S., 2005. Arsenic associations in sediments from the loess aquifer of La Pampa. Argent. Appl. Geochem. 20 (5), 989-1016.

Song, S., Zhu, L., Zhou, W., 2008. Simultaneous removal of phenanthrene and cadmium from contaminated soils by saponin, a plant-derived biosurfactant. Environ. Pollut. 156 (3), 1368-1370.

Thibaut, A., Misselyn-Bauduin, A.M., Grandjean, J., Broze, G., Jerome, R., 2000. Adsorption of an aqueous mixture of surfactants on silica. Langmuir 16 (24), 9192-9198.

Tripathi, S., Brown, D.G., 2008. Effects of linear alkylbenzene sulfonate on the sorption of Brij 30 and Brij 35 onto aquifer sand. Environ. Sci. Technol. 42 (5), 1492-1498.

Turner, A., Xu, J., 2008. Influence of ionic surfactants on the flocculation and sorption of palladium and mercury in the aquatic environment. Water Res. 42 (1-2), 318-326.

Wang, W., Kwak, J.C.T., 1999. Adsorption at the alumina-water interface from mixed surfactant solutions. Colloids Surf. A 156 (1-3), 95-110.

Wang, S.L., Mulligan, C.N., 2009a. Arsenic mobilization from mine tailings in the presence of a biosurfactant. Appl. Geochem. 24 (5), 928-935.

Wang, S.L., Mulligan, C.N., 2009b. Rhamnolipid biosurfactant-enhanced soil flushing for the removal of arsenic and heavy metals from mine tailings. Process Biochem. 44 (3), 296-301.

Yang, K., Zhu, L.Z., Xing, B.S., 2007. Sorption of sodium dodecylbenzene sulfonate by montmorillonite. Environ. Pollut. 145 (2), 571-576.

Yang, G.P., Chen, Q.A., Li, X.X., Cao, X.Y., 2010. Study on the sorption behaviors of Tween-80 on marine sediments. Chemosphere 79 (11), 1019-1025. 
Ying, G.G., 2006. Fate, behavior and effects of surfactants and their degradation products in the environment. Environ. Int. 32 (3), 417-431.

Ying, G.-G., Williams, B., Kookana, R., 2002. Environmental fate of alkylphenols and alkylphenol ethoxylates-a review. Environ. Int. 28 (3), 215-226.

Zhang, H., Selim, H.M., 2005. Kinetics of arsenate adsorption-desorption in soils. Environ. Sci. Technol. 39 (16), 6101-6108.

Zhao, B.W., Zhu, L.Z., Yang, K., 2006. Solubilization of DNAPLs by mixed surfactant: reduction in partitioning losses of nonionic surfactant. Chemosphere 62 (5), 772-779.
Zhao, Z.X., Jia, Y.F., Xu, L.Y., Zhao, S.L., 2011. Adsorption and heterogeneous oxidation of As(III) on ferrihydrite. Water Res. 45 (19), 6496-6504.

Zheng, Y., Stute, M., van Geen, A., Gavrieli, I., Dhar, R., Simpson, H.J., Schlosser, P., Ahmed, K.M., 2004. Redox control of arsenic mobilization in Bangladesh groundwater. Appl. Geochem. 19 (2), 201-214. 